\title{
Uncertainty contributions to low-flow projections in Austria
}

\author{
Juraj Parajka ${ }^{1}$, Alfred Paul Blaschke ${ }^{1}$, Günter Blöschl ${ }^{1}$, Klaus Haslinger ${ }^{2}$, Gerold Hepp ${ }^{3}$, Gregor Laaha ${ }^{4}$, \\ Wolfgang Schöner ${ }^{5}$, Helene Trautvetter ${ }^{3}$, Alberto Viglione ${ }^{1}$, and Matthias Zessner ${ }^{3}$ \\ ${ }^{1}$ Institute for Hydraulic and Water Resources Engineering, TU Wien, Vienna, Austria \\ ${ }^{2}$ Climate Research Department, Central Institute for Meteorology and Geodynamics, Vienna, Austria \\ ${ }^{3}$ Institute for Water Quality, Resource and Waste Management, TU Wien, Vienna, Austria \\ ${ }^{4}$ Institute of Applied Statistics and Computing, University of Natural Resources and Life Sciences (BOKU), Vienna, Austria \\ ${ }^{5}$ Department of Geography and Regional Science, University of Graz, Graz, Austria
}

Correspondence to: J. Parajka (parajka@ @ydro.tuwien.ac.at)

Received: 29 October 2015 - Published in Hydrol. Earth Syst. Sci. Discuss.: 27 November 2015

Revised: 5 April 2016 - Accepted: 12 May 2016 - Published: 26 May 2016

\begin{abstract}
The main objective of the paper is to understand the contributions to the uncertainty in low-flow projections resulting from hydrological model uncertainty and climate projection uncertainty. Model uncertainty is quantified by different parameterisations of a conceptual semi-distributed hydrologic model (TUWmodel) using 11 objective functions in three different decades (1976-1986, 1987-1997, 19982008), which allows for disentangling the effect of the objective function-related uncertainty and temporal stability of model parameters. Climate projection uncertainty is quantified by four future climate scenarios (ECHAM5-A1B, A2, B1 and HADCM3-A1B) using a delta change approach. The approach is tested for 262 basins in Austria.

The results indicate that the seasonality of the low-flow regime is an important factor affecting the performance of model calibration in the reference period and the uncertainty of $Q_{95}$ low-flow projections in the future period. In Austria, the range of simulated $Q_{95}$ in the reference period is larger in basins with a summer low-flow regime than in basins with a winter low-flow regime. The accuracy of simulated $Q_{95}$ may result in a range of up to $60 \%$ depending on the decade used for calibration.

The low-flow projections of $\mathrm{Q}_{95}$ show an increase of low flows in the Alps, typically in the range of 10-30\% and a decrease in the south-eastern part of Austria mostly in the range -5 to $-20 \%$ for the climate change projected for the future period 2021-2050, relative the reference period 1978-2007. The change in seasonality varies between scenarios, but there is a tendency for earlier low flows in the northern Alps and later low flows in eastern Austria. The total uncertainty of
\end{abstract}

$Q_{95}$ projections is the largest in basins with a winter lowflow regime and, in some basins the range of $Q_{95}$ projections exceeds $60 \%$. In basins with summer low flows, the total uncertainty is mostly less than $20 \%$. The ANOVA assessment of the relative contribution of the three main variance components (i.e. climate scenario, decade used for model calibration and calibration variant representing different objective function) to the low-flow projection uncertainty shows that in basins with summer low flows climate scenarios contribute more than $75 \%$ to the total projection uncertainty. In basins with a winter low-flow regime, the median contribution of climate scenario, decade and objective function is 29 , 13 and $13 \%$, respectively. The implications of the uncertainties identified in this paper for water resource management are discussed.

\section{Introduction}

Understanding climate impacts on hydrologic water balance in general and extreme flows in particular is one of the main scientific interests in hydrology. Streamflow estimation during low-flow conditions is important also for a wide range of practical applications, including estimation of environmental flows, effluent water quality, hydropower operations, water supply or navigation. Projections of low flows in future climate conditions are thus essential for planning and development of adaptation strategies in water resource management. However, it is rarely clear how the uncertainties in assump- 
tions used in the projections translate into uncertainty of estimated future low flows.

There are numerous regional and national studies that have analysed the effects of climate change on the streamflow regime, including low flows (e.g. Feyen and Dankers, 2009; Prudhomme and Davies, 2009; Chauveau et al., 2013, among others). Most of them apply outputs from different global or regional climate circulation models, which are based on different emission scenarios. The projections of low flows are then typically simulated by hydrologic models of various complexity. There is an increasing number of studies evaluating different sources of uncertainty in river flow projections resulting from different global climate models (GCMs), downscaling methods or hydrologic model parameterisation (e.g. Dobler et al., 2012; Finger et al., 2012; Coron et al., 2012; Addor et al., 2014; Chiew et al., 2015). Only few studies, however, evaluate the uncertainty of low-flow projections and the relative contribution of its different sources (i.e. climate projection, hydrologic model structure and/or model parameterisations). Such studies include assessment of the impact of different climate projections on low flows evaluated, e.g., in Huang et al. (2013) and Forzieri et al. (2014). While Huang et al. (2013) assessed the low-flow changes and uncertainty in the five largest river basins in Germany, Forzieri et al. (2014) evaluated the uncertainty of an ensemble of 12 bias corrected climate projections in the whole of Europe. Both studies quantified uncertainty in terms of the number of low-flow projections that suggest the same change direction. Their results indicated a consistent pattern of lowflow changes across different regions in Europe. A common feature of such ensemble climate scenarios is an increase in the agreement between ensemble members with increasing future time horizon of climate projections. The impact of hydrologic model structure and climate projections was evaluated in Dams et al. (2015). They applied four hydrologic models calibrated with four objective functions to simulate the impact of three climate projections on low flows for a basin in Belgium. They found that besides the uncertainty introduced by climate change scenarios, hydrologic model selection introduces an additional considerable source of uncertainty in low-flow projections. The model structure uncertainty was particularly important under more extreme climate change scenarios. A similar study was performed by Najafi et al. (2011), who investigated the uncertainty stemming from four hydrologic models calibrated by three objective functions and applied on eight GCM simulations in a basin in Oregon. Their results showed that although in general the uncertainties from the hydrologic models are smaller than from GCM, in the summer low-flow season the impact of hydrologic model parameterisation on overall uncertainty is considerably larger than that of the GCM.

The quantification of the relative contribution of different sources to the overall uncertainty of streamflow projections has been recently evaluated by using analyses of variance (ANOVA) (von Storch and Zwiers, 1999). Bosshard et al. (2013) synthesised previous studies that investigated hydrological climate-impact projections and their sensitivity to different uncertainty sources. They propose an ANOVA framework to separate the uncertainty from climate models, statistical post-processing (bias correction and delta change approach) and hydrological models. Addor et al. (2014) used the ANOVA framework to quantify the uncertainty of streamflow projections resulting from the combination of emission scenarios, regional climate models, post-processing methods and hydrological models of different complexity. They reported that the main source of uncertainty stems from the climate models and natural climate variability, and the impact of emission scenario increases with increasing future time horizon of climate projections. Hingray and Said (2014) proposed a quasi-ergodic two-way ANOVA framework for the partitioning of the total uncertainty of climate projections. This framework has been recently tested for the estimation of climate and hydrological uncertainties of transient low-flow projections in two basins in the southern French Alps (Vidal et al., 2015). The results showed that a large part of the total uncertainty arises from the hydrological modelling and it can be even larger than the contribution from the GCMs.

The objective of this paper is to understand the relative contribution of the impact of hydrologic model calibration and ensemble climate scenarios to the overall uncertainty of low-flow projections in Austria. Here, the uncertainty and variability of low-flow projections is assessed for four climate scenarios, 11 variants of objective functions and 3 decades used for model calibration. Austria is chosen as a case study since it is an ideal test bed for such analysis, as it allows one to disentangle the uncertainties separately in regions with summer and winter low-flow regimes. The assessment of uncertainties for winter and summer low-flow regimes allows one to make generalisation for a similar spectrum of physiographic conditions around the world.

\section{Methodology}

\subsection{Low-flow projections}

In this study, low-flow projections of future climate scenarios are analysed by comparing future to past flows by using model forcing from a delta change approach. This concept allows one to remove biases resulting from simulations when regional climate model (RCM) outputs are used as an input in hydrologic modelling. Instead of using RCM simulations of daily air temperature and precipitation for hydrologic model calibration, the model is first calibrated by using observed climate characteristics in the reference period. In a next step, RCM outputs are used to estimate monthly differences between simulations in the reference (control) and future periods. These differences (delta changes) are then added to the observed model inputs and used for simulating future hydrologic changes. The daily precipitation is scaled by the relative 
Table 1. TUWmodel parameters. Calibration range is given for parameters calibrated by an automatic routine. Parameters with fixed value are not calibrated.

\begin{tabular}{|c|c|c|c|}
\hline Model parameter & Definition & Model component & Calibration range \\
\hline SCF & Snow correction factor (dimensionless) & Snow & $1.0-1.5$ \\
\hline DDF & Degree-day factor $\left(\mathrm{mm}^{\circ} \mathrm{C}_{\text {day }}{ }^{-1}\right)$ & Snow & $0.0-5.0$ \\
\hline$T_{\mathrm{R}}$ & Threshold temperature for rain $\left({ }^{\circ} \mathrm{C}\right)$ & Snow & 2.0 \\
\hline$T_{\mathrm{S}}$ & Threshold temperature for snow $\left({ }^{\circ} \mathrm{C}\right)$ & Snow & 0.0 \\
\hline$T_{\mathrm{M}}$ & Melt temperature $\left({ }^{\circ} \mathrm{C}\right)$ & Snow & $-1.0-3.0$ \\
\hline $\mathrm{LP} / \mathrm{FC}$ & Ratio of limit for potential evapotranspiration and FC (dimensionless) & Soil & $0.0-1.0$ \\
\hline $\mathrm{FC}$ & Maximum soil moisture storage $(\mathrm{mm})$ & Soil & $0.0-600.0$ \\
\hline BETA & Non-linearity parameter of runoff generation (dimensionless) & Soil & $0.0-20.0$ \\
\hline$K_{0}$ & Storage coefficient of additional outlet (days) & Runoff & $0.0-2.0$ \\
\hline$K_{1}$ & Fast storage coefficient (days) & Runoff & $2.0-30.0$ \\
\hline $\mathrm{K}_{2}$ & Slow storage coefficient (days) & Runoff & $30.0-250.0$ \\
\hline$C_{\mathrm{P}}$ & Percolation rate $(\mathrm{mm} / \mathrm{d})$ & Runoff & $0.0-8.0$ \\
\hline$C_{\mathrm{R}}$ & Free routing coefficient $\left(\mathrm{d}^{2} \mathrm{~mm}^{-1}\right)$ & Runoff & 25.0 \\
\hline $\mathrm{LS}_{\mathrm{UZ}}$ & Storage capacity threshold (mm) & Runoff & $1.0-100.0$ \\
\hline $\operatorname{Bmax}$ & Routing parameter (days) & Runoff & 10.0 \\
\hline
\end{tabular}

monthly delta changes, with no change in the frequency of rainy days. The daily air temperature is changed by the absolute value of monthly delta changes. The differences between daily simulations of a hydrologic model in the reference and future periods are then used to interpret potential impacts of changing climate on future river flows.

The future low-flow changes are quantified by the $Q_{95}$ low-flow quantile and seasonality index (SI). The $Q_{95}$ represents river flow that is exceeded on $95 \%$ of the days of the entire reference or future period. This characteristic is one of the low-flow reference characteristic, which is widely used in Europe (Laaha and Blöschl, 2006). SI represents the average timing of low flows within a year (Laaha and Blöschl, 2006, 2007). It is estimated from the Julian dates $D_{j}$ of all days when river flows are equal or below $Q_{95}$ in the reference or future periods. $D_{j}$ represents a cyclic variable. Its directional angle, in radians, is given by

$\theta_{j}=\frac{D_{j} \cdot 2 \pi}{365}$.

The arithmetic mean of Cartesian coordinates $x_{\theta}$ and $y_{\theta}$ of a total of $n$ single days $j$ is defined as

$x_{\theta}=\frac{1}{n} \sum_{j} \cos \left(\theta_{j}\right)$

$y_{\theta}=\frac{1}{n} \sum_{j} \sin \left(\theta_{j}\right)$.

From this, the directional angle of the mean vector may be calculated by

$\theta=\arctan \left(\frac{y_{\theta}}{x_{\theta}}\right) \quad$ 1st and 4th quadrant $: x>0$,

$\theta=\arctan \left(\frac{y_{\theta}}{x_{\theta}}\right)+\pi \quad$ 2nd and 3rd quadrant $: x<0$.
Finally, the mean day of occurrence is obtained from retransformation to Julian date:

$\mathrm{SI}=\theta \cdot \frac{365}{2 \pi}$

and the variability of the date of occurrence about the mean date (i.e. seasonality strength) is characterised by the length parameter $r$. The parameter $r$ is estimated as (Burn, 1997)

$r=\frac{\sqrt{\bar{x}^{2}+\bar{y}^{2}}}{n}$

and ranges from $r=0$ (low strength, uniform distribution around the year) to $r=1$ (maximum strength, all extreme events of low flows occur on the same day).

The SI is estimated for observed and simulated low flows. The differences between model simulations (i.e. $Q_{95}$ and SI estimates) in the reference and future periods are then used to quantify potential impacts of climate change on low flows. Both $Q_{95}$ and SI measurements are estimated independently for the reference and future periods by the lfstat package in R software (Koffler and Laaha, 2014).

\subsection{Hydrologic model}

Low-flow projections are estimated by a conceptual semidistributed rainfall-runoff model (TUWmodel; Viglione and Parajka, 2014). The model simulates water balance components on a daily time step by using precipitation, air temperature and potential evapotranspiration data as an input. The model consists of three modules, which allow for simulating changes in snow, soil storages and groundwater storages. The calibrated model parameters are presented in Table 1. More details about the model structure and examples of application in the past are given, e.g., in Parajka et al. (2007), Parajka and Blöschl (2008), Viglione et al. (2013) and Ceola et al. (2015). 
In this study, the TUWmodel is calibrated by using the SCE-UA (Shuffled Complex Evolution) automatic calibration procedure (Duan et al., 1992). The objective function $\left(Z_{Q}\right)$ used in calibration is selected on the basis of prior analyses performed in different calibration studies in the study region (see e.g. Parajka and Blöschl, 2008; Merz et al., 2011). It consists of the weighted average of two variants of NashSutcliffe model efficiency, $M_{\mathrm{E}}$ and $M_{\mathrm{E}}^{\log }$. While the $M_{\mathrm{E}}$ efficiency emphasise the high flows, the $M_{\mathrm{E}}^{\log }$ efficiency accentuates more the low flows. The maximised objective function $Z_{Q}$ is defined as

$Z_{Q}=w_{Q} \cdot M_{\mathrm{E}}+\left(1-w_{Q}\right) \cdot M_{\mathrm{E}}^{\log }$,

where $w_{Q}$ represents the weight on high or low flows. If $w_{Q}$ equals 1 then the model is calibrated to high flows, if it equals 0 then to low flows only. $M_{\mathrm{E}}$ and $M_{\mathrm{E}}^{\log }$ are estimated as

$$
\begin{gathered}
M_{\mathrm{E}}=1-\frac{\sum_{i=1}^{n}\left(Q_{\mathrm{obs}, i}-Q_{\mathrm{sim}, i}\right)^{2}}{\sum_{i=1}^{n}\left(Q_{\mathrm{obs}, i}-\overline{Q_{\mathrm{obs}}}\right)^{2}}, \\
M_{\mathrm{E}}^{\log }=1-\frac{\sum_{i=1}^{n}\left(\log \left(Q_{\mathrm{obs}, i}\right)-\log \left(Q_{\mathrm{sim}, i}\right)\right)^{2}}{\sum_{i=1}^{n}\left(\log \left(Q_{\mathrm{obs}, i}\right)-\overline{\log \left(Q_{\mathrm{obs}}\right.}\right)^{2}},
\end{gathered}
$$

where $Q_{\mathrm{sim}, i}$ is the simulated discharge on day $i, Q_{\mathrm{obs}, i}$ is the observed discharge, $\overline{Q_{\text {obs }}}$ is the average of the observed discharge over the calibration (or verification) period of $n$ days.

\subsection{Uncertainty estimation}

The uncertainty, defined as the range of simulated low-flow indices, is evaluated for two contributions. The first analyses the uncertainty (i.e. the range of $Q_{95}$ and SI) estimated for different variants of hydrologic model calibration. Here, two cases are evaluated. In order to assess the impact of time stability of model parameters (Merz et al., 2011), the TUWmodel is calibrated separately for 3 different decades (1976-1986, 1987-1997, 1998-2008). The effect of objective functions used for the TUWmodel calibration is evaluated by comparing 11 variants of weights $\left(w_{Q}\right)$ used in $Z_{Q}$. The following $w_{Q}$ are tested: 0.0, 0.1, 0.2, 0.3, 0.4, 0.5, 0.6, $0.7,0.8,0.9$ and 1.0. The hydrologic model is calibrated for all 11 variants in each selected decade. Calibrated models are then used for flow simulations and hence $Q_{95}$ and SI estimation in the reference and future periods.

The second contribution evaluates the uncertainty of $Q_{95}$ and SI changes simulated for different climate scenarios. The effect of calibration uncertainty (case 1) is compared for four selected climate scenarios (more details are given in Sect. 3). The delta change approach is used to derive model forcing for selected future period and simulated future river flows are compared to model simulations in the reference period 1976-2008. The relative changes of $Q_{95}$ and SI values between reference and future periods are estimated for 4 selected climate scenarios, 11 variants of model calibration and 3 selected decades. The relative contribution of the impact of model calibration (i.e. time stability and objective function selection) and climate scenario is evaluated for two low-flow regimes and for individual stations over Austria.

The uncertainty of low-flow projections is then compared to the range of low-flow indices obtained by different calibration variants in the reference period. In addition, the total uncertainty of future low-flow projections is decomposed to individual components by means of analysis of variance (ANOVA; e.g. von Storch and Zwiers, 1999, chap. 9 for a general introduction to ANOVA). The three-way ANOVA approach is employed to decompose total uncertainty of the projected low-flow changes into three main variance components. These variance components represent uncertainty contributions of three main effects: climate scenario (factor A with $I=4$ levels), decade used for model calibration (factor B with $J=3$, levels) and calibration variant representing different objective functions (factor $C$ with $K=11$ levels). The ANOVA model is defined as follows:

$\Delta Q_{95 i j k}=\mu+\alpha_{i}+\beta_{j}+\gamma_{k}+\epsilon_{i j k}$.

In this linear equation (Eq. 10), $\Delta Q_{95_{i j k}}$ denotes the ensemble projected changes in $Q_{95}$ for the future horizon at a gauge. It is modelled by a global mean $\mu$ and the mean effects (deviations of factor-means from the global mean) of climate scenario $\left(\alpha_{i} ; i=1, \ldots, I\right)$, decade $\left(\beta_{j} ; j=1, \ldots, J\right)$ and calibration variant $\left(\gamma_{k} ; k=1, \ldots, K\right)$, and $\epsilon_{i j k}$ are the residual errors of the model. In an ANOVA framework, the total variance of $\Delta Q_{95_{i j k}}$ is characterised by the total sum of squares $\mathrm{SS}_{T}$, and is decomposed into additive variance components of individual effects:

$S_{\mathrm{T}}=\mathrm{SS}_{\mathrm{A}}+\mathrm{SS}_{\mathrm{B}}+\mathrm{SS}_{\mathrm{C}}+\mathrm{SS}_{\mathrm{E}}$

The variance components of the main effects $\mathrm{A}, \mathrm{B}$ and $\mathrm{C}$ are computed as follows:

$$
\begin{aligned}
& \mathrm{SS}_{\mathrm{A}}=J K \sum_{i=1}^{I}\left(\bar{y}_{i . .}-\bar{y}_{\ldots .}\right)^{2}, \\
& \mathrm{SS}_{\mathrm{B}}=I K \sum_{j=1}^{J}\left(\bar{y}_{. j .}-\bar{y}_{\ldots . .}\right)^{2}, \\
& \mathrm{SS}_{\mathrm{C}}=I J \sum_{k=1}^{K}\left(\bar{y}_{. . k}-\bar{y}_{\ldots .}\right)^{2} .
\end{aligned}
$$

The variance component of the residuals representing the unexplained variance is

$$
\mathrm{SS}_{\mathrm{E}}=\sum_{i=1}^{I} \sum_{j=1}^{J} \sum_{k=1}^{K}\left(y_{i j k}-\boldsymbol{y}_{i . .}-\boldsymbol{y}_{. j .}-\boldsymbol{y}_{. . k}+\boldsymbol{y}_{\ldots . .}\right)^{2} .
$$




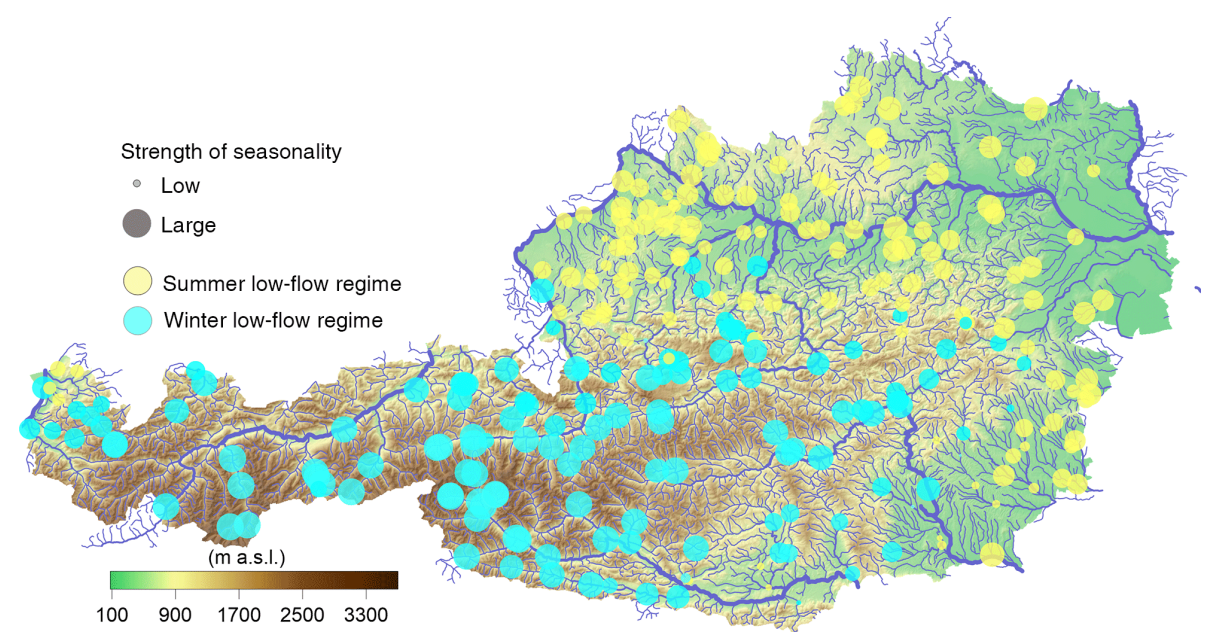

Figure 1. Topography of Austria and location of 262 river flow gauges. Colour and symbol size of the gauges represent seasonality of low-flow SI and its strength $(r)$ in the period 1976-2008, respectively. The SI and its strength are estimated by R lfstat package (Koffler and Laaha, 2014).

Based on the $\mathrm{SS}_{E}$, an estimate of the variance contributions of each effect A, B, C is computed as

$\eta_{A}^{2}=\frac{\mathrm{SS}_{\mathrm{A}}}{\mathrm{SS}_{\mathrm{T}}} ; \quad \eta_{B}^{2}=\frac{\mathrm{SS}_{\mathrm{B}}}{\mathrm{SS}_{\mathrm{T}}} ; \quad \eta_{C}^{2}=\frac{\mathrm{SS}_{\mathrm{C}}}{\mathrm{SS}_{\mathrm{T}}} ; \quad \eta_{E}^{2}=\frac{\mathrm{SS}_{\mathrm{E}}}{\mathrm{SS}_{\mathrm{T}}}$

The measure eta square is also termed the coefficient of determination $R^{2}$ (von Storch and Zwiers, 1999). Eta square tends to overestimate the variance explained by one factor and is therefore a biased estimate of the effect size. A less biased estimator is given by the measure $\omega^{2}$ :

$\omega_{\mathrm{A}}^{2}=\frac{\mathrm{SS}_{\mathrm{A}}-d f_{A} \cdot \mathrm{MS}_{\mathrm{E}}}{\mathrm{SS}_{\mathrm{T}}-\mathrm{MS}_{\mathrm{E}}}$,

where $\mathrm{df}_{\mathrm{A}}$ denotes the degrees of freedom of a factor (e.g. for factor A with I levels, $\left.\mathrm{df}_{\mathrm{A}}=I-1\right)$, and $\mathrm{MS}_{\mathrm{e}}=\mathrm{SS}_{\mathrm{E}} / \mathrm{df}_{\mathrm{e}}$ $\mathrm{MS}_{\mathrm{E}}$ is the residual mean square error. Similar equations to Eq. (17) may be written for factors $B$ and $C$. The quantity $\mathrm{MS}_{\mathrm{e}} \mathrm{MS}_{\mathrm{E}}$ denotes the mean residual sum of squares. It is computed by

$\mathrm{MS}_{\mathrm{E}}=\frac{\mathrm{SS}_{\mathrm{E}}}{\mathrm{df}_{\mathrm{E}}}$

The measure omega square is also termed the adjusted $R^{2}$, in analogy to the adjusted coefficient of determination of multiple regression. Note that the degrees of freedom of the error term $\mathrm{df}_{\mathrm{E}}$ depend on the total number of effects in the ANOVA design. For three-way ANOVA without interactions, $\mathrm{df}_{\mathrm{E}}$ is obtained by

$\mathrm{df}_{\mathrm{E}}=\mathrm{df}_{\mathrm{T}}-\mathrm{df}_{\mathrm{A}}-\mathrm{df}_{\mathrm{B}}-\mathrm{df}_{\mathrm{C}}=I J K-I-J-K+2$.

Clearly, the adjustment of effect size increases if the residual degrees of freedom are small, which is the case when
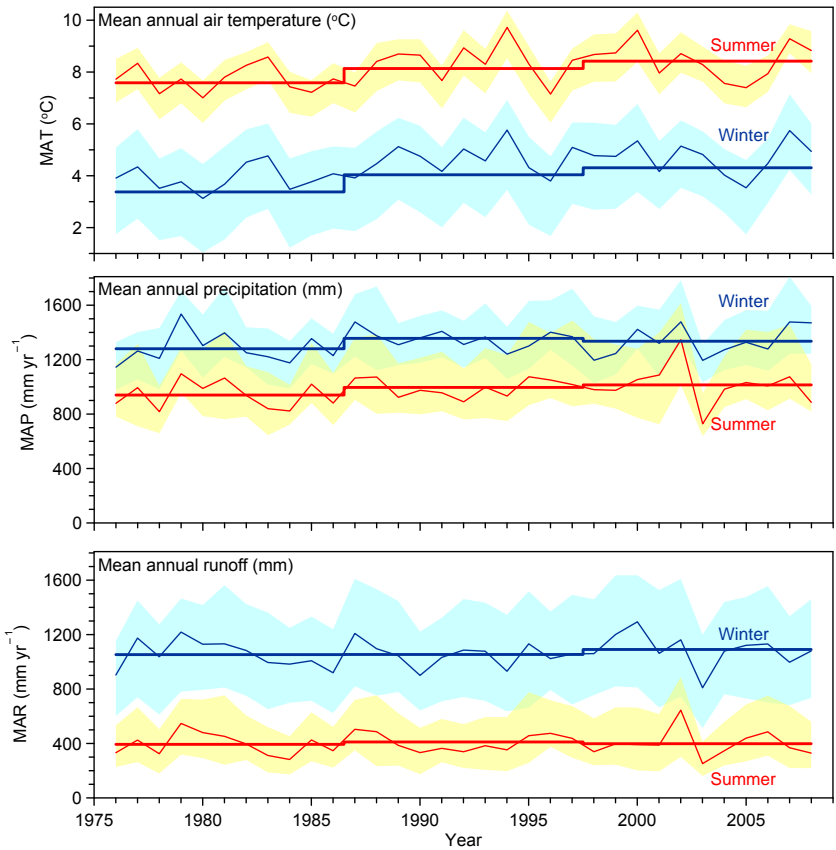

Figure 2. Mean annual air temperature (MAT, top), precipitation (MAP, middle) and runoff (MAR, bottom) for basins with summer (yellow/red) and winter (blue) low-flow minima (Fig. 1). Thin lines represent the median of mean annual values of MAT, MAP and MAR. Thick lines indicate the average for each of the three periods: 1976-1986, 1987-1997 and 1998-2008. Scatter (i.e. $75 \%$ and $25 \%$ percentiles) indicates the variability between the basins.

overall sample size is small. Hence, the difference between both measures of effect size will be negligible for designs with large $\mathrm{df}_{\mathrm{E}}$, as is the case for our study. In our assessment, we will therefore only present $\omega^{2}$, which is the more general 
measure of effect size at each catchment. A spatial synthesis of uncertainty contributions for basins with summer and winter low-flow regime is finally obtained from the distribution of variance components across basins falling into each low-flow regime group.

\section{Data}

The study region is Austria (Fig. 1). Austria represents the diverse climate and physiographic conditions of central Europe, which are reflected in different hydrologic regimes (Gaál et al., 2012). The topography varies from $115 \mathrm{~m}$ a.s.l. in the lowlands to more than $3700 \mathrm{~m}$ a.s.l. in the Alps. Austria is located in a temperate climate zone influenced by the Atlantic, meridional south circulation and the continental weather systems of Europe. Mean annual air temperature varies between -8 to $10^{\circ} \mathrm{C}$. The mean annual precipitation ranges from $550 \mathrm{~mm} \mathrm{yr}^{-1}$ in the Danube lowlands, to more than $3000 \mathrm{~mm} \mathrm{yr}^{-1}$ on the windward slopes of the Alps.

The analysis is based on daily river flow measurements at 262 gauges (Fig. 1). This data set represents a subset of data used in Laaha and Blöschl (2006), which consists of gauges for which hydrographs are not seriously affected by abstractions and karst effects during the low-flow periods. Figure 1 shows two main low-flow regimes in Austria; yellow circles indicate 130 stations with dominant summer (June-November) low-flow occurrence and blue circles indicate 132 gauges with winter (December-May) flow minima. These two groups represent basins with distinct lowflow seasons, which are controlled by different hydrologic processes. While the winter flow minima in the mountains are controlled by freezing processes and snow storage, summer low flows occur during long-term persistent dry periods when evapotranspiration exceeds precipitation. The different low-flow generating processes, together with the hydroclimatic variety of the study area, gives rise to an enormous spatial complexity of low flows in Austria. The largest values occur in the Alps, with typical values ranging from 6 to $201 \mathrm{~s}^{-1} \mathrm{~km}^{-2}$. The lowest values occur in the east ranging from 0.02 to $81 \mathrm{~s}^{-1} \mathrm{~km}^{-2}$, although the spatial pattern is much more intricate.

Climate data used in hydrologic modelling consists of mean daily precipitation and air temperature measurements at 1091 and 212 climate stations in the period 1976-2008. Model inputs have been prepared by spatial interpolation and zonal averaging described in detail in previous modelling studies (please see e.g. Merz et al., 2011 or Parajka et al., 2007). These data serve as a basis for hydrologic model calibration and as a reference for future change simulations. Figure 2 shows basin averages of mean annual air temperature, precipitation and runoff in the period 1976-2008. The two groups of basins (winter vs. summer low-flow regimes) clearly differ in the climate regime. Basins with summer low flows are characterised by higher air temperatures, less
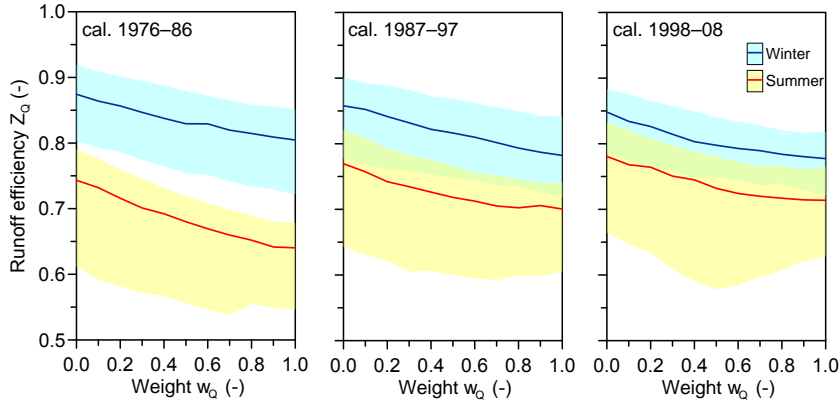

Figure 3. Runoff model efficiency $\left(Z_{Q}\right)$ for different calibration weights $w_{Q}$ in three different calibration periods. Lines represent the medians, scatter (i.e. $75-25 \%$ percentiles) shows the $Z_{Q}$ variability over basins with dominant winter (blue) and summer (orange) low-flow regime.

precipitation and less runoff. The comparison of 3 different decades indicates that mean annual air temperatures have increased by $1{ }^{\circ} \mathrm{C}$ in the period 1976-2008. This increase is similar for both groups of basins. Interestingly, the mean annual precipitation has increased over the last 3 decades, which is likely compensated by increased evapotranspiration, as the mean annual runoff remains rather constant.

The RCM scenarios used in this study are based on the results of the reclip.century project (Loibl et al., 2011). The ensemble climate projections are represented by COSMOCLM RCM runs forced by the ECHAM5 and HADCM3 global circulation models for three different Intergovernmental Panel on Climate Change (IPCC) emission scenarios (A1B, B1 and A2; Nakicenovic et al., 2000). These represent a large spread of different emission pathways from a "business as usual" scenario with prolonged greenhouse gas emissions (A2), a scenario with moderate decline of emissions after 2050 (A1B) and a scenario indicating considerably reduced emissions from the present onwards (B1).

Table 2 summarises the annual and seasonal differences (delta changes) of mean basin precipitation and air temperature between the future (2021-2050) and reference (19782007) periods. Table 2 indicates that the largest warming is obtained by simulations driven by HADCM3. The median of air temperature increase in summer exceeds $2{ }^{\circ} \mathrm{C}$. In numerous basins, a small decrease in air temperature in winter is simulated by ECHAM5 A2 and B1 simulations. The changes in mean annual precipitation are within the range $\pm 9 \%$ in all selected basins. The increase tends to be larger in winter than in the summer period. 
Table 2. Summary of seasonal and annual changes in the mean basin precipitation and air temperature as simulated by four selected RCM runs. The first value and values in the brackets are the median and range ( $\mathrm{min} / \mathrm{max}$ ) of differences between the future (2021-2050) and reference (1978-2007) periods in 262 basins. Winter and summer seasons are defined as December-May and June-November, respectively.

\begin{tabular}{lllll}
\hline Delta change & WEGC ${ }^{*}$ ECHAM5 A1B & ZAMG ${ }^{* *}$ ECHAM5 A2 & AIT ${ }^{* * *}$ HADCM3 A1B & ZAMG ECHAM5 B1 \\
\hline $\begin{array}{l}\text { Air temperature } \\
\text { winter }\left({ }^{\circ} \mathrm{C}\right)\end{array}$ & $+1.5(0.9 / 1.7)$ & $+0.7(-1.1 / 2.1)$ & $+1.3(0.8 / 1.5)$ & $+1.0(-0.8 / 2.5)$ \\
$\begin{array}{l}\text { Air temperature } \\
\text { summer }\left({ }^{\circ} \mathrm{C}\right)\end{array}$ & $+1.2(0.8 / 1.7)$ & $+0.9(-0.1 / 2.2)$ & $+2.1(1.4 / 2.4)$ & $+1.3(0.4 / 2.5)$ \\
$\begin{array}{l}\text { Air temperature } \\
\text { year }\left({ }^{\circ} \mathrm{C}\right)\end{array}$ & $+1.3(0.9 / 1.5)$ & $+0.8(-0.4 / 2.2)$ & $+1.7(1.2 / 1.9)$ & $+1.2(0.0 / 2.5)$ \\
$\begin{array}{l}\text { Precipitation } \\
\text { winter }(\%)\end{array}$ & $+8.2(-0.7 / 16.2)$ & $-1.5(-5.8 / 6.4)$ & $+1.3(-9.6 / 6.8)$ & $0.0(-8.5 / 3.3)$ \\
$\begin{array}{l}\text { Precipitation } \\
\text { summer }(\%)\end{array}$ & $-6.2(-9.9 / 3.7)$ & $+0.2(-8.9 / 5.7)$ & $-5.0(-13.5 / 0.2)$ & $-2.3(-6.3 / 2.5)$ \\
$\begin{array}{l}\text { Precipitation } \\
\text { year }(\%)\end{array}$ & $+0.9(-4.6 / 8.7)$ & $-0.9(-4.1 / 3.4)$ & $-2.0(-9.3 / 1.8)$ & $-1.2(-5.5 / 2.8)$ \\
\hline
\end{tabular}

* WEGC $=$ Wegener Center for Climate and Global Change

** ZAMG $=$ Zentralanstalt für Meteorologie und Geodynamik

*** AIT = Austrian Institute of Technology
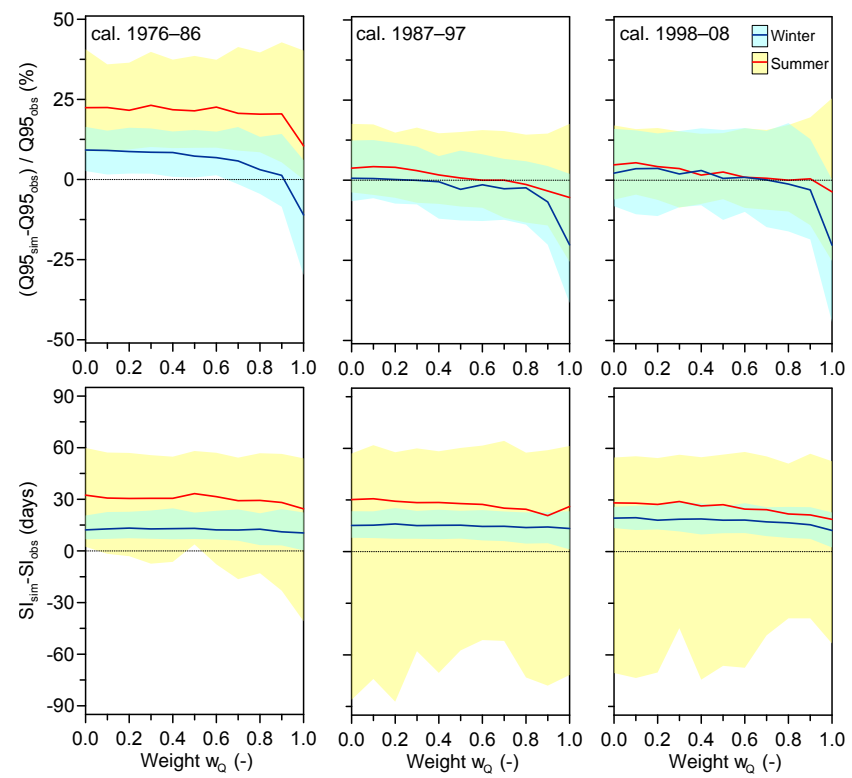

Figure 4. Difference between simulated and observed low-flow characteristics (top panels low-flow quantile $Q_{95}$, bottom panels seasonality index SI) for different calibration variants $\left(w_{Q}\right)$ and calibration periods. Lines represent the median, scatter (i.e. $75-25 \%$ percentiles) show the variability over basins with dominant winter (blue) and summer (orange) low-flow regime. The differences are estimated between model simulations and observations in the entire reference period 1976-2008.

\section{Results}

\subsection{Low-flow simulations and uncertainty in the reference period}

The runoff model efficiency $\left(Z_{Q}\right)$ in the three calibration periods obtained for different variants of the objective function is presented in Fig. 3. The results show that $Z_{Q}$ is larger and thus runoff simulations are more accurate in basins with winter (blue colour) than summer low-flow minimum (red colour). Most of the basins with a winter low-flow regime are situated in the alpine western and central part of Austria, where the runoff regime is snow dominated. Such a regime has stronger runoff seasonality (see e.g. Fig. 5 in Laaha et al., 2015) and less difference in rainfall regime, which allows one to model the rainfall-runoff process easier than in basins with rainfall-dominated runoff regime. $Z_{Q}$ increases with decreasing weight $w_{Q}$, which indicates that the runoff model performance likely tends to be better for low than high flows. The comparison of $Z_{Q}$ in the three calibration periods indicates that the difference in model performance between basins with winter and summer low-flow regime is the largest in the period 1976-1986. While $Z_{Q}$ for basins with winter low-flow regime is very similar in all three calibration periods, $Z_{Q}$ has an increasing tendency in basins with summer low-flow regime. For example, the median of $Z_{Q}$ for $w_{Q}=1.0$ increases from 0.64 in the period 1976-1986 to 0.71 in the period $1998-2008$. This increase is likely related to the increasing number of climate stations and data quality (Merz et al., 2009).

How the different calibration variants and periods translate into low-flow $95 \%$-quantile $Q_{95}$ and seasonality SI is examined in Fig. 4. The model calibrated for an 11-year period is used to simulate daily flows in the entire reference pe- 


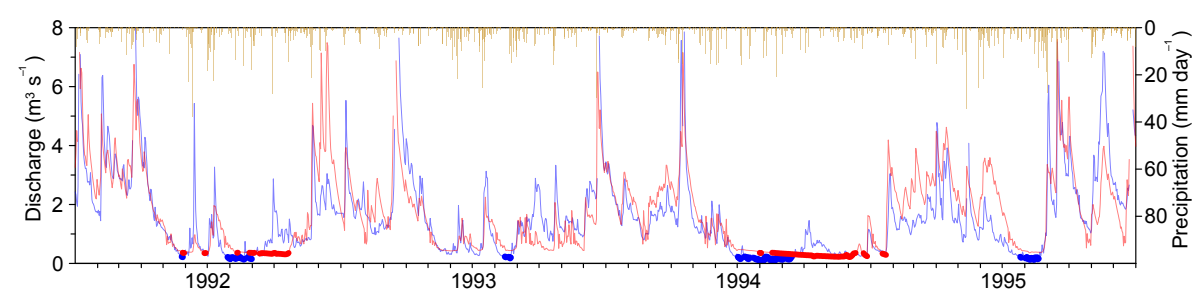

Figure 5. Comparison of observed (blue) and simulated (red) flow for Hoheneich/Braunaubach, $291.5 \mathrm{~km}^{2}$ ). Thick lines show flows below low-flow quantile $Q_{95}$. Model simulations are based on calibration variant $w_{Q}=0.5$ in the period 1998-2008. The relative difference between $Q_{95}$ estimated from simulated and observed flows is $8 \%$.

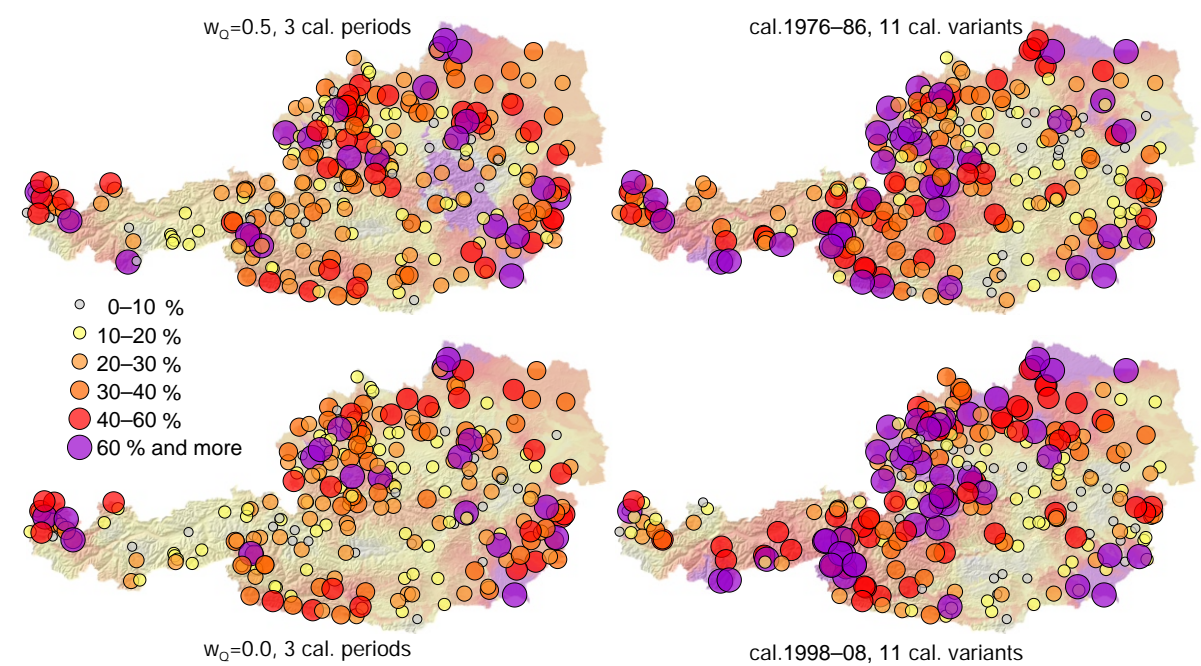

Figure 6. Uncertainty of $Q_{95}$ model simulations estimated from 11 calibration variants calibrated in the same calibration period (right panels: top - calibration period 1976-1986, bottom - calibration period 1998-2008) and from three calibration periods calibrated by the same calibration variant (left panels: top $w_{Q}=0.5$, bottom $w_{Q}=0.0$ ). The uncertainty is expressed as the range of relative differences $(\%)$ between simulated and observed $Q_{95}$ obtained by particular calibration variants in the period 1976-2008. Colour patterns in the background show the interpolated ranges by using top-kriging method (Skoien et al., 2014; Parajka et al., 2015).

riod 1976-2008. The results show that the model calibrated in the period 1976-1986 significantly overestimates $Q_{95}$ of the reference period particularly in basins with summer lowflow regime. The period 1976-1986 is characterised by lower air temperatures with less evapotranspiration and relatively higher runoff generation rates, which translates into different soil moisture storage (FC model parameter) and runoff generation (BETA) model parameters. Such effects are consistent with findings of Merz et al., (2011). The hydrologic model applied to the entire reference period hence produces larger runoff contribution, which tends to overestimate $Q_{95}$ particularly in the warmer and drier parts of the reference period and drier and warmer parts of Austria. The overestimation is consistent for large range of $w_{Q}\left(w_{Q}\right.$ in the range 0.0 0.9 ) and the median of $Q_{95}$ difference exceeds $20 \%$. Also the scatter around the median is rather large, where $25 \%$ of the basins with the summer low-flow regime have $Q_{95}$ differences larger than $35 \%$. The simulated $Q_{95}$ in basins with winter low flows fit closer to the observed estimates. The median is less than $10 \%$ for variants $w_{Q}<1$. Interestingly, the model simulations based on calibration periods 19871997 and 1998-2008 are much closer to the observed values. The results for both groups of basins are very similar and essentially unbiased in terms of $95 \%$ low-flow quantile. The exception is the calibration variant $w_{Q}=1$ that tends to underestimate $Q_{95}$. There are many significant differences between calibration to low-flow only $\left(w_{Q}=0.0\right)$ and other weights, with the exception of $w_{Q}=1$, which represents a typical calibration of using classical Nash-Sutcliffe coefficient.

The results of the seasonality estimation are presented in the bottom panels of Fig. 4. It is clear that this hydrologic model tends to estimate the low-flow period later. This shift is larger in basins with summer low-flow regimes. While the median of SI difference in basins with winter low flows is around 10-12 days in the period 1976-1986 and increases to 12-19 days in the period 1998-2008, the median of SI difference in basins with summer low flows is in the range of 18-32 days. The scatter is, however, much larger for basins with summer low-flow regime. Here the model simulates the 


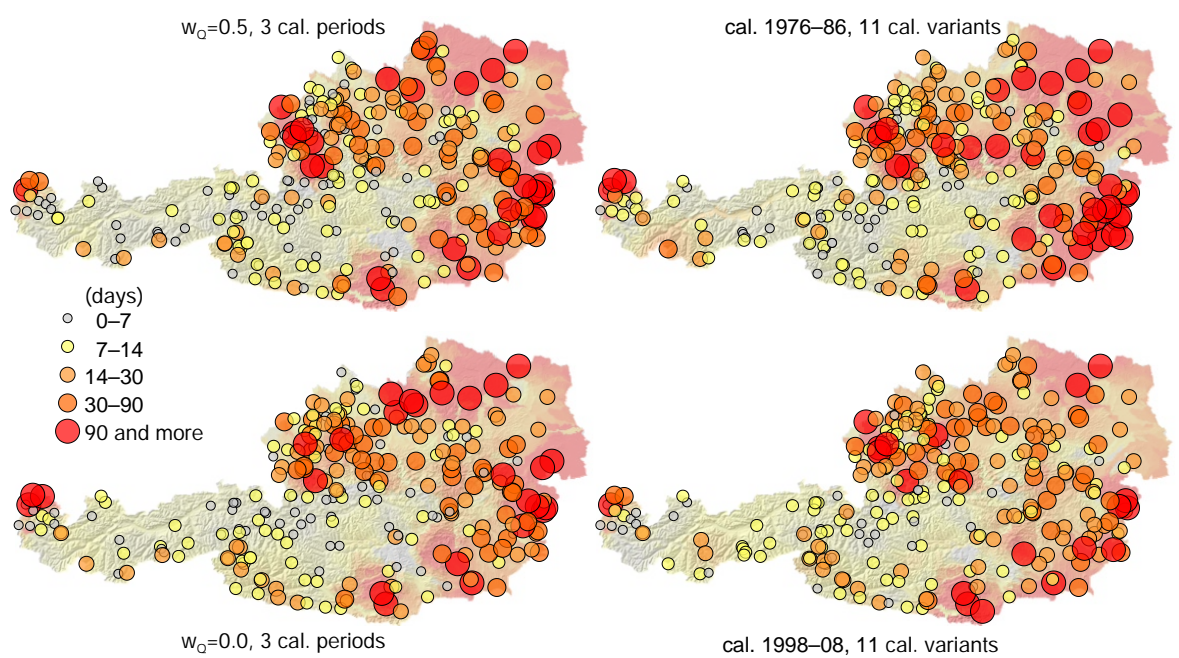

Figure 7. Uncertainty of simulations of low-flow seasonality (SI) estimated from 11 calibration variants calibrated in the same calibration period (right panels: top - calibration period 1976-1986, bottom - calibration period 1998-2008) and from three calibration periods calibrated by the same calibration variant (left panels: top $w_{Q}=0.5$, bottom $w_{Q}=0.0$ ). The uncertainty is expressed as the range of differences (days) between simulated and observed SI in the period 1976-2008. Colour patterns in the background show the interpolated ranges by using top-kriging.

season of low-flow occurrence with more than 2 months shift (earlier or later) in almost $50 \%$ of the basins. A typical example of such shift is provided in Fig. 5. The periods with flows below $95 \%$ quantile are often very short and the timing of simulated low flows does not fit well with these periods. In some cases there is also a difference in the length of observed and simulated low-flow periods. Some small rainfall-runoff events in the summer or autumn cause an interruption of the observed low-flow periods, but the model simulates a complete absorption of the precipitation event by the soil storage and hence a longer low-flow period.

The spatial pattern of the variability of $Q_{95}$ estimation in the reference period 1976-2008 is presented in Fig. 6. Figure 6 shows the range of differences between simulated and observed $Q_{95}$ for the different calibration variants. The results indicate that the $Q_{95}$ differences vary more between the different objective functions (right panels); however, in many basins the range exceeds $60 \%$ even if the model is calibrated by one objective function but in the different calibration periods. As already indicated in Fig. 4, the differences are larger in basins with summer low flows, particularly for variants calibrated in the period 1976-1986. For particular basins, the differences are not strongly related to the weight $w_{Q}$ used in the calibration, with an exception of $w_{Q}=1$, which tends to have the largest difference to observed $Q_{95}$. Some examples of the model performance for individual basins are given in the companion paper by Laaha et al. (2015).

Spatial variability of the model variability in terms of lowflow seasonality is presented in Fig. 7. The results clearly indicate that basins with winter low-flow regime (i.e. situated in the Alps) vary significantly less for different calibration settings than the basins with summer low-flow regime.
The range of differences is typically less than 14 days in the mountains, compared to more than 90 days in many basins with the summer low-flow regime.

The comparison of SI and $Q_{95}$ ranges indicates that large SI variability does not systematically mean large variability in terms of $Q_{95}$. For example, a cluster of basins situated in the south-eastern part of Austria (Styria) has a large SI range of difference (i.e. more than 90 days) for 11 calibration variants in the period 1976-1986, but the variability in $Q_{95}$ is in many basins less than $20 \%$ for this case. The same applies for the opposite case of small SI and large $Q_{95}$ variability in the alpine basins.

\subsection{Low-flow projections and uncertainty in the future period}

Low-flow projections for selected climate scenarios and different calibration weights $w_{Q}$ are presented in Fig. 8. Rather than to evaluate in detail the projections in terms of absolute values of low-flow changes, the main focus is to assess the range of possible changes caused by different scenarios and objective function used for model calibration. The results show projections based on model calibration in 19982008 , but the results are almost identical with results for the other two calibration periods (i.e. the average difference is around $1 \%$ ). Figure 8 clearly shows the difference in projections for basins with summer and winter low-flow regime, particularly for $Q_{95}$ changes. It is hence important to evaluate the projections and their variability separately for different regimes. The comparison of different scenarios indicates that they are similar in terms of projecting an increase of winter low flows and a tendency for no change or decreas- 

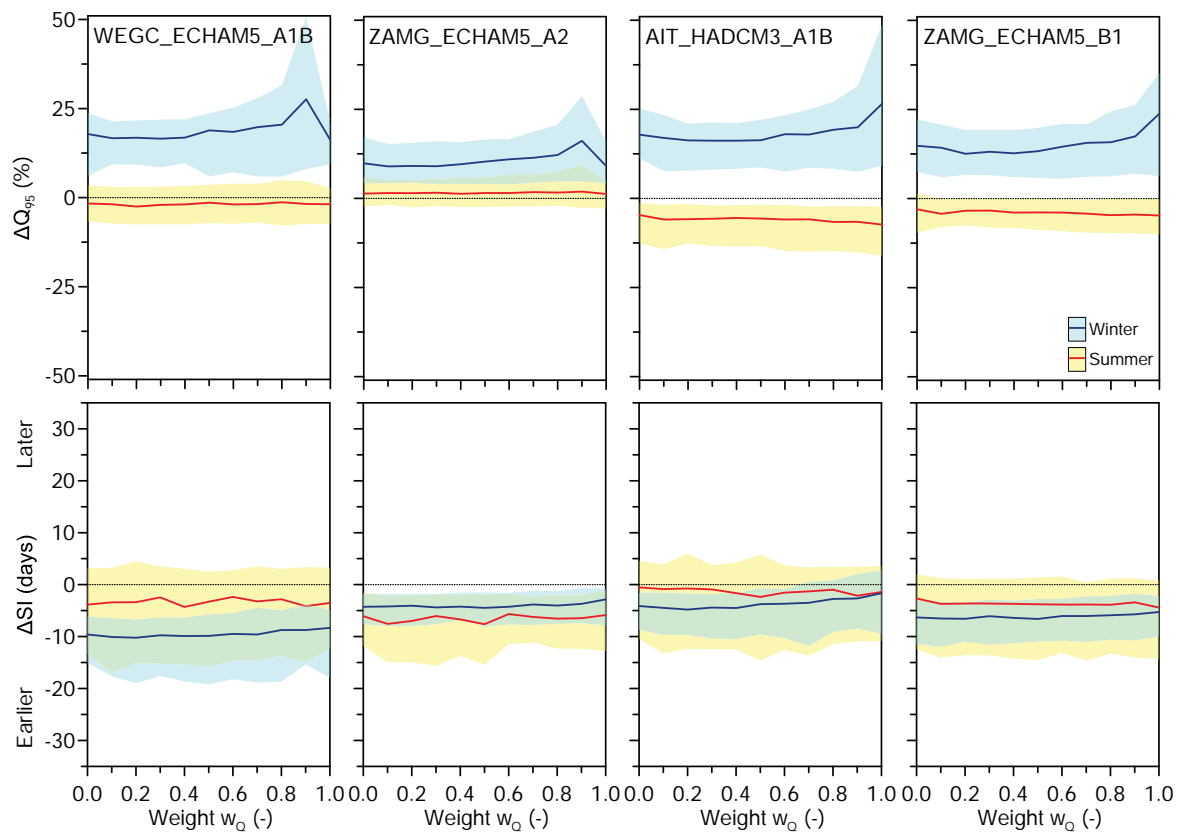

Figure 8. Projections of low flows for selected climate scenarios and calibration variants. Line represents the medians, scatter (i.e. 75-25\% percentiles) shows the variability over 262 basins. Top and bottom panels show projected changes of low-flow quantiles $Q_{95}$ and seasonality index SI in basins with winter (blue) and summer (orange) low-flow regimes, respectively. Projections indicate future changes with respect to the reference period 1976-2008. Calibration variants are calibrated in the period 1998-2008.
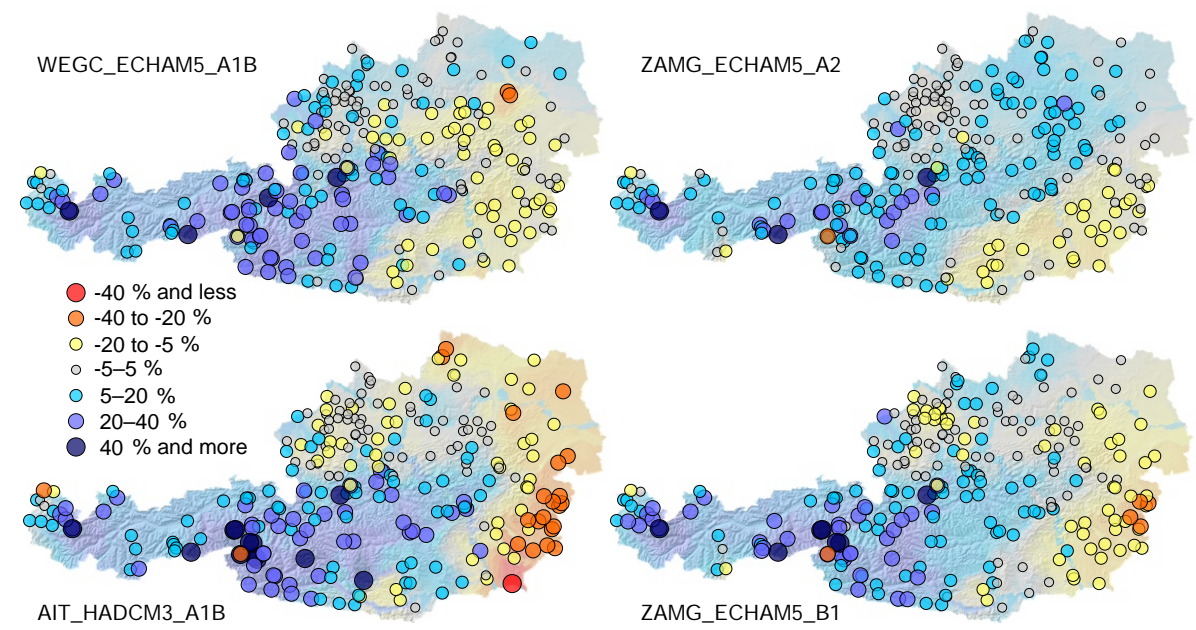

Figure 9. Projections of low-flow quantiles $Q_{95}$ changes for four climate scenarios in 262 Austrian basins. Model simulations are based on variant $w_{Q}=0.5$ calibrated in the period 1998-2008. Colour patterns in the background show the interpolated projections by using top-kriging.

ing low flows in the summer period. The increase of winter $Q_{95}$ slightly varies between climate scenarios and tends to increase for calibration variants with larger $w_{Q}$. The difference in median between $w_{Q}<0.4$ and $w_{Q}>0.8$ is approximately $9 \%$. The projections of $Q_{95}$ changes in basins with summer low flows have significantly smaller variability and do not depend on $w_{Q}$. The change in low-flow seasonality (Fig. 8, bottom panels) is less pronounced. The median of projections is around 5 and 10 days earlier than in the reference period for basins with summer and winter low-flow regime, respectively. Interestingly, the variability between basins and $w_{Q}$ is significantly smaller than that obtained for different calibration variants in the reference period (Fig. 4).

Examples of spatial patterns of low-flow projections are presented in Figs. 9 and 10. The projections of $Q_{95}$ changes (Fig. 9) indicate an increase of low flows in the Alps, typ- 


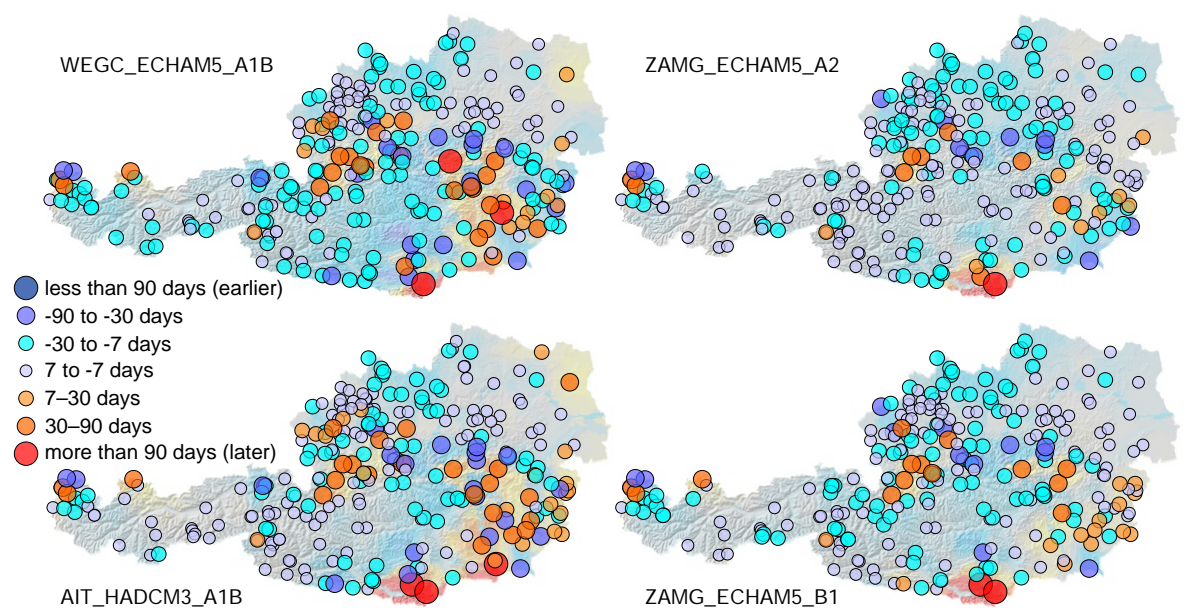

Figure 10. Projections of changes in low-flow seasonality (SI) for four climate scenarios in 262 Austrian basins. Model simulations are based on variant $w_{Q}=0.5$ calibrated in the period 1998-2008. Colour patterns in the background show the interpolated projections by using top-kriging.

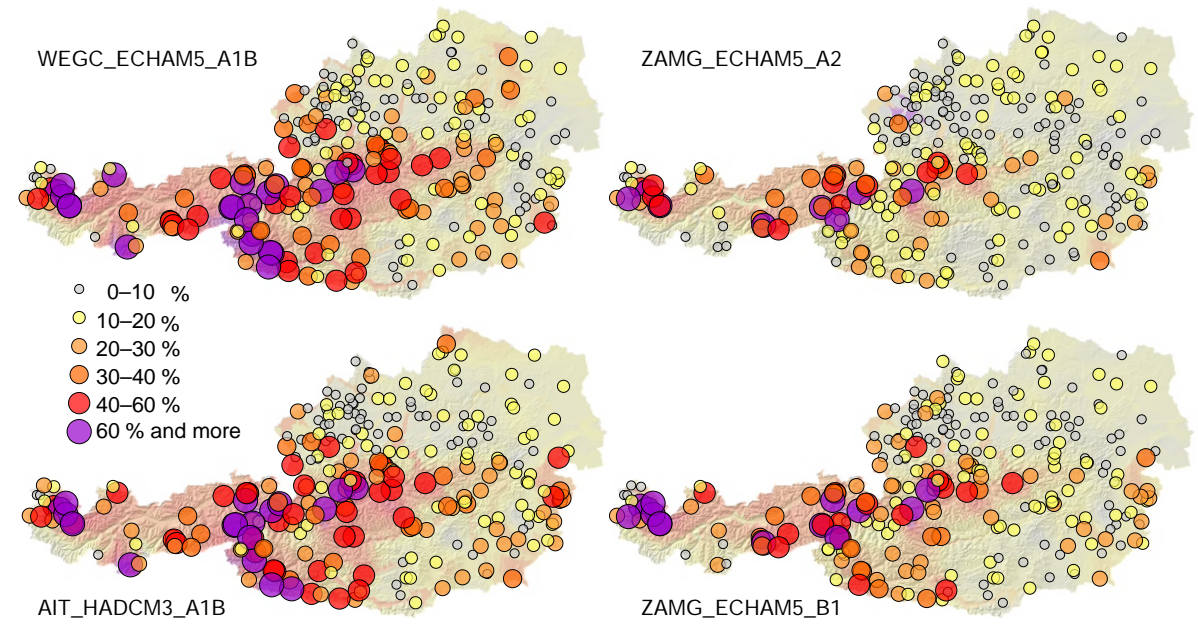

Figure 11. Uncertainty of $Q_{95}$ model projections of low flows for four different climate scenarios. The uncertainty is expressed as the range of relative differences $(\%)$ between $Q_{95}$ simulated in the future and reference period obtained for 11 calibration variants calibrated in three calibration periods. Colour patterns in the background show the interpolated ranges by using top-kriging.

ically in the range of $10-30 \%$. A decrease is simulated in south-eastern part of Austria (Styria) mostly in the range of $-5-(-20) \%$. The most spatially different projection is provided by the HADCM3 A1B climate scenario, which simulates the strongest gradient between an increase of $Q_{95}$ in the Alps in winter and a decrease in the south-eastern region in summer. The change in the seasonality varies between the scenarios, but there is a tendency for earlier low flows in the northern Alps and a shift to later occurrence of low flows in eastern Austria (Fig. 10). As already indicated in Fig. 8, the shift in seasonality is greater than 1 month only in a few basins.

Figures 9 and 10 show projections of low flows for four climate scenarios, but only one set of hydrologic model pa- rameters. The evaluation of the impacts of different calibration variants on the variability of low-flow projections is presented in Figs. 11 and 12. These figures indicate the range of $Q_{95}$ (Fig. 11) and the seasonality occurrence (Fig. 12) changes obtained by 11 calibration variants and 3 calibration periods. The range of $Q_{95}$ changes is interestingly the largest in basins with the winter low-flow regime. In the Alps, the increase of $Q_{95}$ is often in the range of $15 \%$ to more than $60 \%$. On the other hand, the future $Q_{95}$ estimates vary only slightly between the calibration variants in basins with the summer low flows. The change is less than $20 \%$ in most of the basins. The impact of the selection of objective function is, however, much larger for the estimation of the seasonality changes. Depending on the calibration variant, the change in 


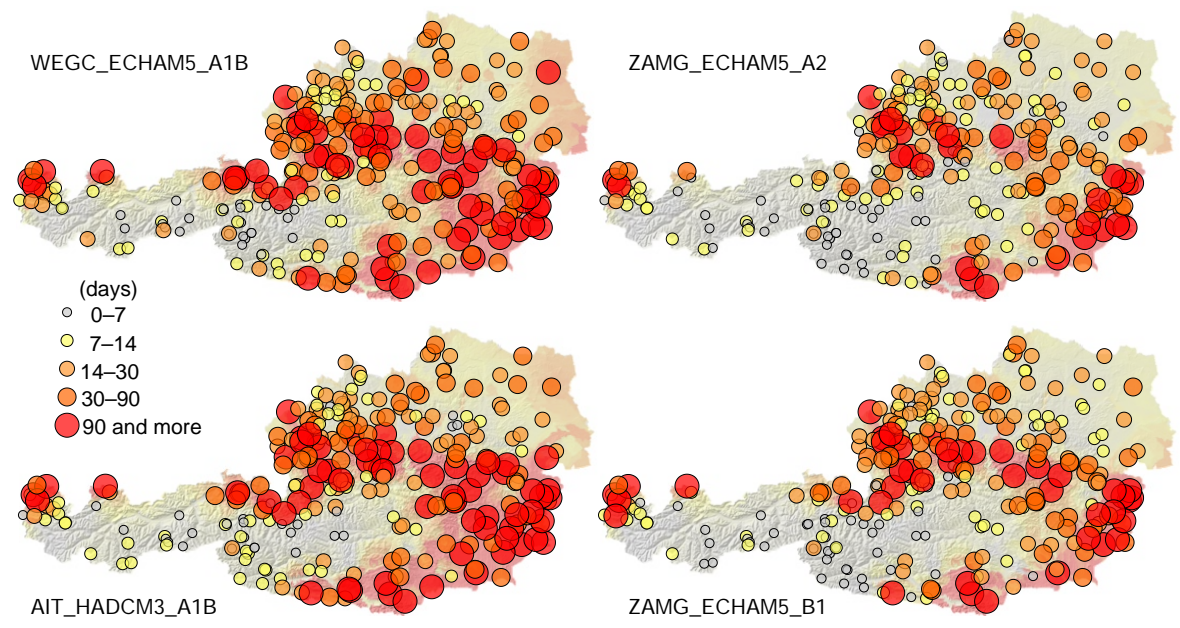

Figure 12. Uncertainty of model projections of low-flow seasonality for four different climate scenarios. The uncertainty is expressed as the range of relative differences $(\%)$ between seasonality occurrence (SI) simulated in the future and reference period obtained for 11 calibration variants calibrated in three calibration periods. Colour patterns in the background show the interpolated ranges by using top-kriging.

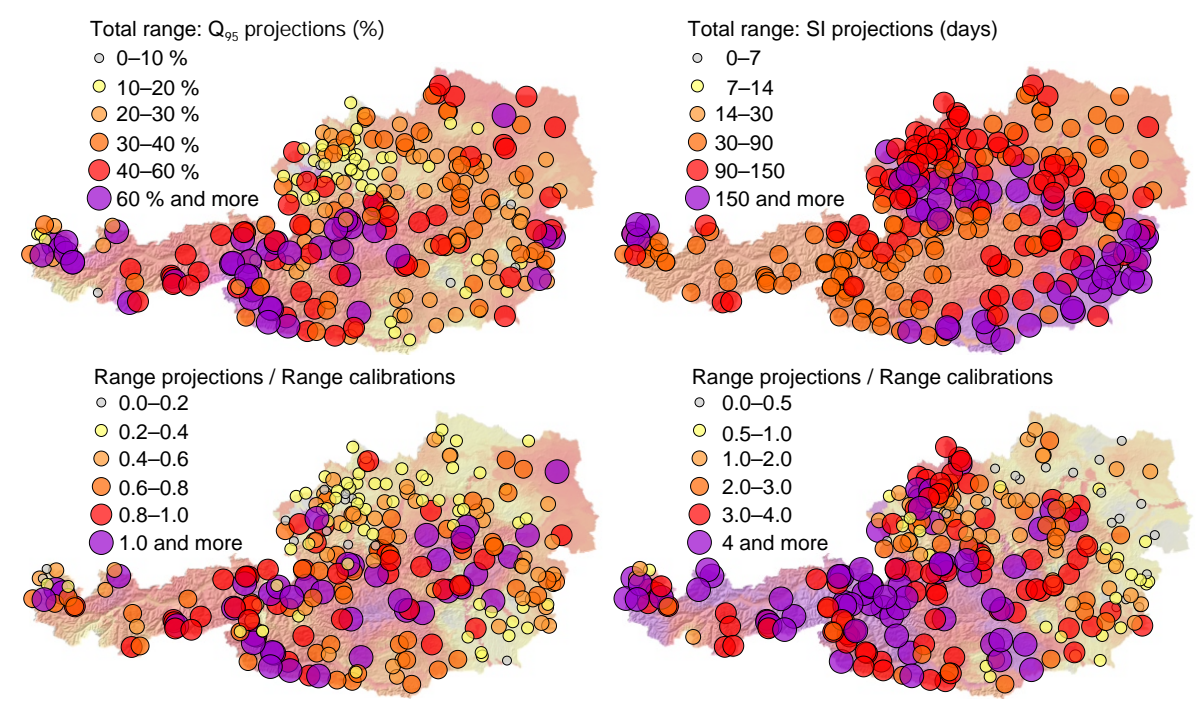

Figure 13. Total uncertainty of model projections of low flows for four different climate scenarios, 11 calibration variants and three calibration periods. The uncertainty is expressed as the range of $Q_{95}$ (left panel) and seasonality (right panel) of differences between model simulations in the future and reference periods. Bottom panels show the ratio between the range of climate projections to the range of differences in the reference period. Colour patterns in the background show the interpolated ranges by using top-kriging.

seasonality can vary within more than 3 months, e.g. in the south-eastern part of Austria.

The total uncertainty of low-flow projections of $Q_{95}$ and SI is presented in Fig. 13. While the top panels show the range of low-flow characteristics for all climate scenarios, calibration variants and periods, the bottom panels show the ratio between the uncertainty of future low-flow projections to the range of low-flow indices simulated in the reference period. The results show that the $Q_{95}$ range is less than $25 \%$ in approximately one-third of analysed basins. On the other hand, $20 \%$ of basins have a range larger than $50 \%$. These are the basins with the winter low-flow regime. The variabil- ity in the date of low-flow occurrence is less than 3 months in $40 \%$ of the basins. In almost $20 \%$ of the basins, however, it is larger than 5 months. The ratio between the range of projections to the range of calibration differences (bottom panels in Figs. 13 and 14) indicates that only in $15 \%$ of the cases is the climate projection uncertainty of $Q_{95}$ larger than the range obtained in the calibration period. Most of these basins are situated in the mountains (mean basin elevation above $1000 \mathrm{~m}$ a.s.l.) and have winter low-flow regime. The range of calibrated $Q_{95}$ is larger in almost all basins with the summer low-flow regime, which are characterised by lower mean basin elevation and larger aridity (i.e. ratio of mean an- 

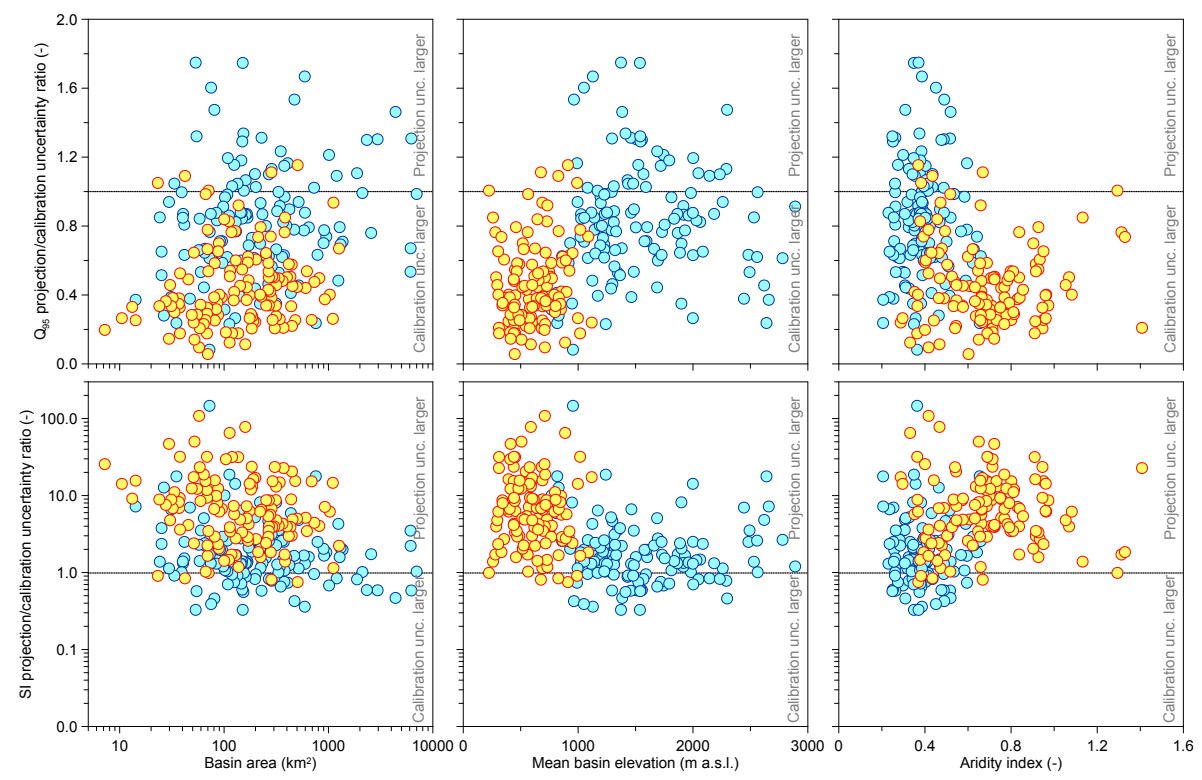

Figure 14. Relationship between the uncertainty ratio between calibration and projection uncertainty and basin area (left panels), mean basin elevation (middle panels) and aridity index (right panels). Top and bottom panels show the uncertainty ratio for the low-flow quantile ( $\left.Q_{95}\right)$ and seasonality index (SI), respectively. Basins with winter low-flow seasonality are plotted in blue, basins with summer low-flow seasonality are in yellow.
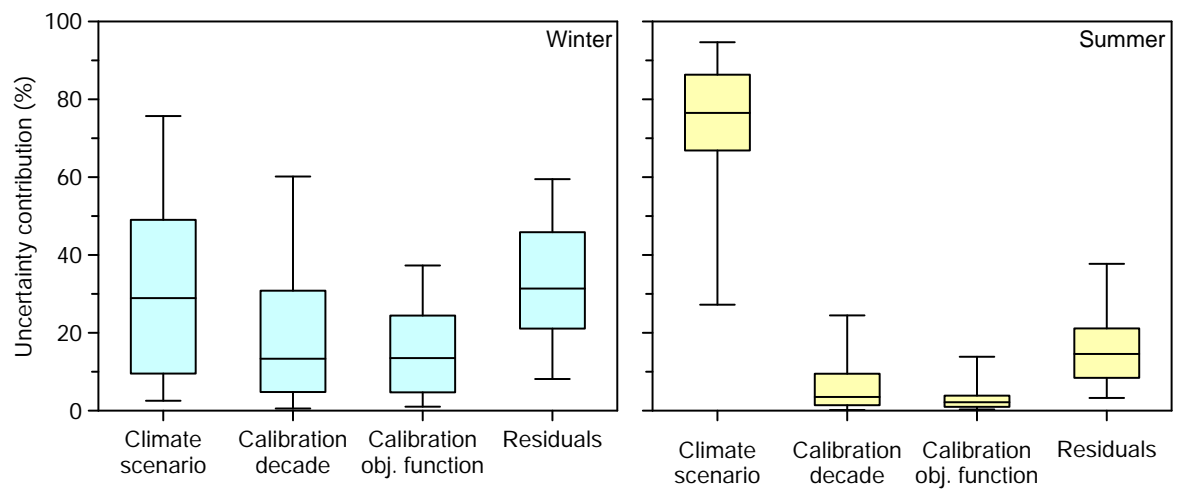

Figure 15. Relative contribution of the three variance components (i.e. climate scenario, calibration decade and objective function) to the overall uncertainty of future low-flow projection in basins with winter (left panel) and summer (right panel) low-flow regime. The boxes and whiskers show 25 and $75 \%$ percentiles and 5 and $95 \%$ percentiles of the uncertainty contributions in 130 (summer low-flow regime) and 132 (winter low-flow regime) basins, respectively.

nual potential evaporation to mean annual precipitation). On the other hand, the climate projection uncertainty dominates for the low-flow seasonality and is more than 3 times larger in $50 \%$ of basins, particularly in the Alps. The SI projection uncertainty is only in $15 \%$ of the basins lower than the SI range obtained in the calibration period. The SI uncertainty ratio tends to be lower with increasing mean basin elevation and the basin area, but there is no apparent relationship with the aridity of the basins.

The relative contribution of the three main variance components (i.e. climate scenario, decade used for model calibration and calibration variant representing different objective function) to the overall uncertainty of future low-flow projections is evaluated in Fig. 15. Left and right panels show the distribution of ANOVA variance components for basins with winter (left panel) and summer (right panel) low-flow regime, respectively. The results indicate that the variability from climate scenarios has a dominant contribution to the overall projection uncertainty in basins with summer lowflow regime. While in basins with winter low flows the median contribution of the three variance components is $29 \%$ (climate scenario), $13 \%$ (calibration decade) and $13 \%$ (objective function), in basins with summer low-flow regime 
the median contribution from climate scenario is larger than $76 \%$.

\section{Discussion and conclusions}

The objective of the study is to explore the relative role of hydrologic model calibration and climate scenarios in the uncertainty of low-flow projections. While many previous studies simulate only the change in hydrologic regime or extreme characteristics due to changes in climate, in this study we focus on the quantification of the range of low-flow projections (i.e. uncertainty) due to differences in the objective function used in model calibration, temporal stability of model parameters and an ensemble of climate projections.

There are a number of studies that compare the uncertainty of projected runoff changes due to different model structure, objective function or GCM and emission scenarios. These studies found that the hydrologic model uncertainty tends to be considerably smaller than that from GCM or emission scenarios (Najafi et al., 2011; Prudhomme and Davies, 2009). Such results, however, refer to the seasonal or monthly runoff and are based on only a limited number of basins. The quantification of the uncertainty in low flows is still rather rare. Some studies (e.g. Huang et al., 2013; Forzieri et al., 2014) evaluate the low-flow uncertainty in terms of the number of projections with the same change direction. They showed that the uncertainty is controlled mainly by the differences in emission scenarios and it decreases with increasing projection horizon. Our results indicate that, although the uncertainty from different climate scenarios is larger than $40 \%$ in many basins, the range of low-flow indices from model calibration can exceed $60 \%$. This result particularly relates to the assessment of low-flow quantile changes.

Some recent low-flow studies suggest to more explicitly distinguish between the processes leading to low-flow situations (see e.g. Fleig et al., 2006; Laaha et al., 2006; Van Loon et al., 2015; Forzieri et al., 2014). Following this recommendation, we analysed the effects of model calibration and climate scenarios separately for basins with dominant winter and summer low-flow regimes. Our results indicate that the calibration runoff efficiency in basins with winter low-flow regime is larger (more accurate), and varies between basins less than in basins with summer low-flow regime. The calibration uncertainty in basins with summer low flows exceeds in many basins $60 \%$ even if the model is calibrated by the same objective function but in different calibration periods. This finding confirms and quantifies the potential impact of time stability of model parameters reported by Merz et al. (2011). The model parameters calibrated in colder periods with relatively larger runoff generation rates tend to overestimate low flows, particularly in basins with a summer low-flow regime and in warmer and drier parts of the simulation period. The results indicate that the time stability of model parameters is not sensitive to the weighting of normal
$\left(M_{\mathrm{E}}\right)$ and logarithmic transformed $\left(M_{\mathrm{E}}^{\log }\right)$ Nash-Sutcliffe efficiency in the objective function used for calibration. The exception is the case of using only $M_{\mathrm{E}}$ with no weight on $M_{\mathrm{E}}^{\log }$, which does not allow for accurate low-flow simulations. This finding partly supports the studies that propose logarithmically transformed discharge values for calibrating hydrologic models with a focus on low flows (please see review in Pushpalatha et al., 2012). Our results show that the impact of the objective function is larger for SI estimation in basins with summer low-flow regime in the reference period and for future projections of $Q_{95}$ in basins with winter low-flow regime. Depending on the calibration variant, the change in seasonality can vary within more than 3 months, which clearly indicates a shift in the main hydrologic processes causing the low flows.

The climate change signals captured in selected scenarios are well within the range of the projections of the ENSEMBLES regional climate simulations for Europe (Van der Linden and Mitchell, 2009; Heinrich and Gobiet, 2011). Jacob et al. (2014) showed that the most recent regional climate simulations over Europe, accomplished by the EURO-CORDEX initiative (Moss et al., 2010), are rather similar to the older ENSEMBLES simulations with respect to the climate change signal and the spatial patterns of change. Although this ensemble of four scenario runs seems rather small, the selection accomplished by the reclip:century consortium was not arbitrary, but based on quantitative metrics. Prein et al. (2011) investigated the performance of all GCMs in CMIP3 for central Europe based on a performance index including various parameters. They found that for the given domain the ECHAM5 and the HADCM3 showed the highest scores, which justified the selection of these GCMs for driving the RCM. In addition, these two models show different climate sensitivity, where the warming over the course of the 21st century is lower in ECHAM5 and higher in HADCM3. This feature in combination with the utilisation of three different scenarios for ECHAM5 provides broad ensemble bounds, although the climate change signal of the different scenarios for the given investigation period (2021-2050) is rather similar, particularly for air temperature (cf. Table 1). The projected future decrease of $Q_{95}$ is most pronounced in the AIT_HADCM3_A1B run, particularly in basins with summer low-flow regime in the low lands. As indicated in Heinrich and Gobiet (2011), the climate sensitivity of HADCM3 is higher than that of ECHAM5, which translates into a higher warming rate of $2.1^{\circ} \mathrm{C}$ in summer (cf. Table 1) compared to $1.2^{\circ} \mathrm{C}$ in the ECHAM5-driven run. The higher evaporative demand due to the increased air temperature signal translates into the strongest change of the summer low-flow signal.

The comparison of the ranges of low-flow indices projected for different climate scenarios and simulated by different calibration settings (i.e. objective function and calibration decade) in the reference period indicates that the variability 
of low-flow magnitudes is larger for simulations in the reference period, while the range of seasonality is larger for future projections. Previous ENSEMBLES and CORDEX studies showed that RCM uncertainty is far from being negligible for hydrology-related variables. Even if only one RCM is tested here and the variability and uncertainty of GCM and emission scenarios can be large, the results clearly indicate the importance of selecting objective functions in hydrologic model calibration for simulating low-flow projections.

In our study, we use a three-way ANOVA approach to decompose the contribution of climate scenarios and hydrologic model settings to the total uncertainty of low-flow projections. While previous studies (e.g. Hingray and Said, 2014; Lafaysse et al., 2014; Vidal et al., 2015) assessed the variance components of a temporal change from the multimember ensemble runs in individual basins, in our study, we lumped the temporal change to one time slice (future horizon) and assessed the variance components in a spatial context of 262 basins. The spatial synthesis of the uncertainty contribution is evaluated for two groups of basins, representing two main (summer and winter) low-flow regimes in Austria. We found that the relative contribution of three variance components - climate scenarios, calibration decade and calibration objective function differs for basins with different low-flow regimes. The uncertainty from climate scenarios dominates in basins with summer low flows; however, in basins with winter low flows the relative contribution from hydrological modelling is significantly larger. This is consistent with previous studies that show a substantial uncertainty contribution of hydrological models in basins dominated by snow- and ice melt (Addor et al., 2014; Vidal et al., 2015).

The assessment in Austria enabled us to account for one conceptual hydrologic model and two different low-flow regimes. In the future we plan to extend such comparative assessment to more types of low flows (e.g. as classified in Van Loon and Van Lanen, 2012), their combinations linked with changes in land use and management at the wider, European scale, as well as to account for hydrologic models of different complexity, wider range of climate scenarios and different downscaling techniques. This will allow us to shed more light on the factors controlling the possible scenarios of low-flow and water resource changes in the future.

From a practical point of view, the projections of $Q_{95}$ changes and related uncertainties are an essential input to water quality modelling. The exceedance of environmental quality standards (BGB1 II No. 99/2010, 2010; Zessner, 2008) in case of emissions from point sources (e.g. waste water treatment plants) increases the vulnerability of water resources, particularly during low-flow conditions. We therefore also plan to evaluate the impact of climate projection and hydrologic model uncertainties on the assessment of water quality and its changes.
Acknowledgements. We would like to thank the Austrian Climate and Energy Fund (Project B060362-CILFAD, Project no. R13AC6K11034-AQUASTRESS) and the Austrian Science Foundation (FWF Project no. P 23723-N21) for financial support. At the same time, we would like to thank the Hydrographical Service of Austria (HZB) and the Central Institute for Meteorology and Geodynamics (ZAMG) for providing hydrologic and climate data.

Edited by: J.-P. Vidal

\section{References}

Addor, N., Rössler, O., Köplin, N., Huss, M., Weingartner, R., and Seibert, J.: Robust changes and sources of uncertainty in the projected hydrological regimes of Swiss catchments, Water Resour. Res., 50, 7541-7562, doi:10.1002/2014WR015549, 2014.

BGB1 II Nr. 99/2010: Bundesgesetzblatt für die Republik Österreich, Qualitätszielverordnung Ökologie Oberflächengewässer QZV Ökologie OG, Jahrgang 2010.

Bosshard, T., Carambia, M., Goergen, K., Kotlarski, S., Krahe, P., Zappa, M., and Schär, C.: Quantifying uncertainty sources in an ensemble of hydrological climate-impact projections, Water Resour. Res., 49, 1523-1536, doi:10.1029/2011WR011533, 2013.

Burn, D. H.: Catchment similarity for regional flood frequency analysis using seasonality measures, J. Hydrol., 202, 212-230, 1997.

Ceola, S., Arheimer, B., Baratti, E., Blöschl, G., Capell, R., Castellarin, A., Freer, J., Han, D., Hrachowitz, M., Hundecha, Y., Hutton, C., Lindström, G., Montanari, A., Nijzink, R., Parajka, J., Toth, E., Viglione, A., and Wagener, T.: Virtual laboratories: new opportunities for collaborative water science, Hydrol. Earth Syst. Sci., 19, 2101-2117, doi:10.5194/hess-19-2101-2015, 2015.

Chauveau, M., Chazot, S., Perrin, C., Bourgin, P., Sauquet, E., Vidal, J., Rouchy, N., Martin, E., David, J., Norotte, T., Maugis, P., and de Lacaze, X.: What impacts of climate change on surface hydrology in France by 2070?, La Houille Blanche, 4, 5-15, 2013.

Chiew, F. H. S., Zheng, H., and Vaze, J.: Implication of calibration period on modelling climate change impact on future runoff, Proc. IAHS, 371, 3-6, doi:10.5194/piahs-371-3-2015, 2015.

Coron, L., Andréassian, V., Perrin, C., Lerat, J., Vaze, J., Bourqui, M., and Hendrickx, F.: Crash testing hydrological models in contrasted climate conditions: An experiment on 216 Australian catchments, Water Resour. Res., 48, W05552, doi:10.1029/2011WR011721, 2012.

Dams, J., Nossent, J., Senbeta, T. B., Willems, P., and Batelaan, O.: Multi-model approach to assess the impact of climate change on runoff, Journal of Hydrology, 529(3),1601-1616 doi:10.1016/j.jhydrol.2015.08.023, 2015.

Dobler, C., Hagemann, S., Wilby, R. L., and Stötter, J.: Quantifying different sources of uncertainty in hydrological projections in an Alpine watershed, Hydrol. Earth Syst. Sci., 16, 4343-4360, doi:10.5194/hess-16-4343-2012, 2012.

Duan, Q., Sorooshian, S., and Gupta, V. K.: Effective and efficient global optimization for conceptual rainfall-runoff models, Water Resour. Research, 28, 1015-1031, 1992. 
Feyen, L. and Dankers, R.: Impact of global warming on streamflow drought in Europe, J. Geophys. Res., 114, D17116, doi:10.1029/2008JD011438, 2009.

Finger, D., Heinrich, G., Gobiet, A., and Bauder, A.: Projections of future water resources and their uncertainty in a glacierized catchment in the Swiss Alps and the subsequent effects on hydropower production during the 21 st century, Water Resour. Res., 48, W02521, doi:10.1029/2011WR010733, 2012.

Fleig, A. K., Tallaksen, L. M., Hisdal, H., and Demuth, S.: A global evaluation of streamflow drought characteristics, Hydrol. Earth Syst. Sci., 10, 535-552, doi:10.5194/hess-10-535-2006, 2006.

Forzieri, G., Feyen, L., Rojas, R., Flörke, M., Wimmer, F., and Bianchi, A.: Ensemble projections of future streamflow droughts in Europe, Hydrol. Earth Syst. Sci., 18, 85-108, doi:10.5194/hess-18-85-2014, 2014.

Gaál, L., Szolgay, J., Kohnová, S., Parajka, J., Merz, R., Viglione, A., and Blöschl, G.: Flood timescales: Understanding the interplay of climate and catchment processes through comparative hydrology, Water Resour. Res., 48, W04511, doi:10.1029/2011WR011509, 2012.

Heinrich, G. and Gobiet, A.: reclip:century 1 Research for Climate Protection: Century Climate Simulations: Expected Climate Change and its Uncertainty in the Alpine Region, ACRP final report reclip:century part D, Graz, Austria, 48 pp., 2011.

Hingray, B. and Said, M.: Partitioning internal variability and model uncertainty components in a multimember multimodel ensemble of climate projections, J. Climate, 27, 6779, doi:10.1175/JCLID-13-00629.1, 2014.

Huang, S., Krysanova, V., and Hattermann, F. F.: Projection of low flow conditions in Germany under climate change by combining three RCMs and a regional hydrological model, Acta Geophys., 61, 151-193, 2013.

Jacob, D., Petersen, J., Eggert, B., Alias, A., Christensen, O. B., Bouwer, L., Braun, A., Colette, A., Déqué, M., Georgievski, G., Georgopoulou, E., Gobiet, A., Menut, L., Nikulin, G., Haensler, A., Hempelmann, N., Jones, C., Keuler, K., Kovats, S., Kröner, N., Kotlarski, S., Kriegsmann, A., Martin, E., Meijgaard, E., Moseley, C., Pfeifer, S., Preuschmann, S., Radermacher, C., Radtke, K., Rechid, D., Rounsevell, M., Samuelsson, P., Somot, S., Soussana, J.-F., Teichmann, C., Valentini, R., Vautard, R., Weber, B. and Yiou, P.: EURO-CORDEX: new high-resolution climate change projections for European impact research, Reg. Environ. Change, 14, 563-578, doi:10.1007/s10113-013-0499-2, 2014.

Koffler, D. and Laaha, G.: lfstat: Calculation of Low Flow Statistics for daily stream flow data. $\mathrm{R}$ package version 0.5 . available at: http://CRAN.R-project.org/package=lfstat (last access: 20 November 2015), 2014.

Laaha, G. and Blöschl, G.: Seasonality indices for regionalizing low flows, Hydrolog. Process., 20, 3851-3878, doi:10.1002/hyp.6161, 2006.

Laaha, G. and Blöschl, G.: A national low flow estimation procedure for Austria, Hydrol. Sci. J., 52, 625-644, 2007.

Laaha, G., Parajka, J., Viglione, A., Koffler, D., Haslinger, K., Schöner, W., Zehetgruber, J., and Blöschl, G.: A three-pillar approach to assessing climate impacts on low flows, Hydrol. Earth Syst. Sci. Discuss., 12, 13069-13122, doi:10.5194/hessd12-13069-2015, 2015.
Lafaysse, M., Hingray, B., Mezghani, A., Gailhard, J., and Terray, L.: Internal variability and model uncertainty components in future hydrometeorological projections: The Alpine Durance basin, Water Resour. Res., 50, 3317-3341, doi:10.1002/2013WR014897, 2014.

Loibl, W., Formayer, H., Schöner, W., Truhetz, H., Anders, I., Gobiet, A., Heinrich, G., Köstl, M., Nadeem, I., Peters Anders, J., Schicker, I., Suklitsch, M., and Züger, H.: reclip:century 1 Research for Climate Protection: Century Climate Simulations: Models, Data and GHG Scenarios, Simulations, ACRP final report reclip:century part A, Vienna, 22 pp., 2011.

Merz, R., Parajka, J., and Blöschl, G.: Time stability of catchment model parameters: Implications for climate impact analyses, Water Resour. Res., 47, W02531, doi:10.1029/2010WR009505, 2011.

Moss, R. H., Edmonds, J. A., Hibbard, K. A., Manning, M. R., Rose, S. K., van Vuuren, D. P., Carter, T. R., Emori, S., Kainuma, M., Kram, T., Meehl, G. A., Mitchell, J. F. B., Nakicenovic, N., Riahi, K., Smith, S. J., Stouffer, R. J., Thomson, A. M., Weyant, J. P., and Wilbanks, T. J.: The next generation of scenarios for climate change research and assessment, Nature, 463, 747-756, 2010.

Najafi, M. R., Moradkhani, H., and Jung, I. W.: Assessing the uncertainties of hydrologic model selection in climate change impact studies, Hydrol. Process. 25, 2814-2826, doi:10.1002/hyp.8043, 2011.

Nakicenovic, N., Alcamo, J., Davis, G., de Vries, B., Fenhann, J., Gaffin, S., Gregory, K., Grübler, A., Jung, T. Y., Kram, T., La Rovere, E. L., Michaelis, L., Mori, S., Morita, T., Pepper, W., Pitcher, H., Price, L., Raihi, K., Roehrl, A., Rogner, H.-H., Sankovski, A., Schlesinger, M., Shukla, P., Smith, S., Swart, R., van Rooijen, S., Victor, N., and Dadi, Z.: IPCC Special Report on Emissions Scenarios, Cambridge University Press: Cambridge, UK and New York, 599 pp., 2000.

Parajka, J. and Blöschl, G.: The value of MODIS snow cover data in validating and calibrating conceptual hydrologic models, J. Hydrol., 358, 240-258, 2008.

Parajka, J., Merz, R., and Blöschl, G.: Uncertainty and multiple objective calibration in regional water balance modelling: case study in 320 Austrian catchments, Hydrol. Process., 21, 435446, doi:10.1002/hyp.6253, 2007.

Parajka, J., Merz, R., Skøien, J. O., and Viglione, A.: The role of station density for predicting daily runoff by TOPKRIGING interpolation in Austria, J. Hydrol. Hydromech., 63, 1-7, doi:10.1515/johh-2015-0024, 2015.

Prein, A. F., Gobiet, A., and Truhetz, H.: Analysis of uncertainty in large scale climate change projections over Europe, Met. Zet., 20, 383-395, 2011.

Prudhomme, Ch. and Davies, H.: Assessing uncertainties in climate change impact analyses on the river flow regimes in the UK. Part 2: future climate, Clim. Change, 93, 177-195, doi:10.1007/s10584-008-9464-3, 2009.

Skoien, J.O., Blöschl, G., Laaha, G., Pebesma, E., Parajka, J., and Viglione, A.: rtop: An R package for interpolation of data with a variable spatial support, with an example from river networks, Comp. Geosci., 67, 180-190, doi:10.1016/j.cageo.2014.02.009, 2014.

Van der Linden, P., and Mitchell, J. F. B. (Eds.): ENSEMBLES: Climate Change and its Impacts: Summary of research and re- 
sults from the ENSEMBLES project, Met Office Hadley Centre, Exeter, UK, 160 pp., 2009.

Van Loon, A. F. and Van Lanen, H. A. J.: A process-based typology of hydrological drought, Hydrol. Earth Syst. Sci., 16, 19151946, doi:10.5194/hess-16-1915-2012, 2012.

Van Loon, A. F., Ploum, S. W., Parajka, J., Fleig, A. K., Garnier, E., Laaha, G., and Van Lanen, H. A. J.: Hydrological drought types in cold climates: quantitative analysis of causing factors and qualitative survey of impacts, Hydrol. Earth Syst. Sci., 19, 1993-2016, doi:10.5194/hess-19-1993-2015, 2015.

Vidal, J.-P., Hingray, B., Magand, C., Sauquet, E., and Ducharne, A.: Hierarchy of climate and hydrological uncertainties in transient low flow projections, Hydrol. Earth Syst. Sci. Discuss., 12, 12649-12701, doi:10.5194/hessd-12-12649-2015, 2015.
Viglione, A., Parajka, J., Rogger, M., Salinas, J. L., Laaha, G., Sivapalan, M., and Blöschl, G.: Comparative assessment of predictions in ungauged basins - Part 3: Runoff signatures in Austria, Hydrol. Earth Syst. Sci., 17, 2263-2279, doi:10.5194/hess-172263-2013, 2013.

Viglione, A. and Parajka, J.: TUWmodel: Lumped Hydrological Model for Education Purposes. R package version 0.1-4. available at: http://CRAN.R-project.org/package=TUWmodel, (last access: 20 November 2015), 2014.

von Storch, H. and Zwiers, F. W.: Statistical analysis in climate research, Cambridge University Press, Cambridge, 484 pp., 1999.

Zessner, M.: Transboundary pollution and water quality policies in Austria, Water Sci. Technol., 58, 1917-1923, doi:10.2166/wst.2008.562, 2008. 